\title{
Minute ventilation/carbon dioxide production in chronic heart failure
}

\author{
Piergiuseppe Agostoni ${ }^{1,2}$, Susanna Sciomer ${ }^{3}$, Pietro Palermo ${ }^{1}$, Mauro Contini ${ }^{1}$, \\ Beatrice Pezzuto ${ }^{1}$, Stefania Farina ${ }^{1}$, Alessandra Magini ${ }^{1}$, Fabiana De Martino ${ }^{1}$, \\ Damiano Magri ${ }^{4}$, Stefania Paolillo ${ }^{5,6}$, Gaia Cattadori ${ }^{7}$, Carlo Vignati ${ }^{1,2}$, \\ Massimo Mapelli ${ }^{1,2}$, Anna Apostolo ${ }^{1}$ and Elisabetta Salvioni ${ }^{1}$
}

Number 2 in the Series "Ventilatory efficiency and its clinical prognostic value in cardiorespiratory disorders" Edited by Pierantonio Laveneziana and Paolo Palange

Affiliations: ${ }^{1}$ Centro Cardiologico Monzino, IRCCS, Milan, Italy. ${ }^{2}$ Dept of Clinical Science and Community Health, University of Milan, Milan, Italy. ${ }^{3}$ Dept of Clinical, Internal, Anesthesiological and Cardiovascular Sciences, Sapienza University of Rome, Rome, Italy. ${ }^{4}$ Dept of Clinical and Molecular Medicine, Sapienza University of Rome, Rome, Italy. ${ }^{5}$ Dept of Advanced Biomedical Sciences, Federico II University of Naples, Naples, Italy. ${ }^{6}$ Mediterranea Cardiocentro, Naples, Italy. ${ }^{7}$ Unità Operativa Cardiologia Riabilitativa, Multimedica IRCCS, Milan, Italy.

Correspondence: Piergiuseppe Agostoni, Centro Cardiologico Monzino, IRCCS, Via Parea 4, 20138 Milan, Italy. E-mail: piergiuseppe.agostonidaccfm.it

@ERSpublications

In chronic heart failure, the $V_{\mathrm{E}}^{\prime}$ versus $V_{\mathrm{CO}_{2}}^{\prime}$ relationship gives information about $V_{\mathrm{E}}^{\prime} /$ perfusion mismatch and exercise-induced dead space changes, has a relevant prognostic power, and may be modified in the presence of comorbidities https://bit.ly/2NwZWHa

Cite this article as: Agostoni P, Sciomer S, Palermo P, et al. Minute ventilation/carbon dioxide production in chronic heart failure. Eur Respir Rev 2021; 30: 200141 [https://doi.org/10.1183/16000617.0141-2020].

ABSTRACT In chronic heart failure, minute ventilation $\left(V_{\mathrm{E}}^{\prime}\right)$ for a given carbon dioxide production $\left(V^{\prime} \mathrm{CO}_{2}\right)$ might be abnormally high during exercise due to increased dead space ventilation, lung stiffness, chemo- and metaboreflex sensitivity, early metabolic acidosis and abnormal pulmonary haemodynamics. The $V_{\mathrm{E}}^{\prime}$ versus $V$ ' $\mathrm{CO}_{2}$ relationship, analysed either as ratio or as slope, enables us to evaluate the causes and entity of the $V^{\prime}{ }_{\mathrm{E}} /$ perfusion mismatch. Moreover, the $V_{\mathrm{E}}^{\prime}$ axis intercept, i.e. when $V_{\mathrm{CO}_{2}}^{\prime}$ is extrapolated to 0, embeds information on exercise-induced dead space changes, while the analysis of end-tidal and arterial $\mathrm{CO}_{2}$ pressures provides knowledge about reflex activities. The $V_{\mathrm{E}}^{\prime}$ versus $V_{\mathrm{CO}_{2}}^{\prime}$ relationship has a relevant prognostic power either alone or, better, when included within prognostic scores. The $V_{\mathrm{E}}^{\prime}$ versus $V_{\mathrm{CO}_{2}}^{\prime}$ slope is reported as an absolute number with a recognised cut-off prognostic value of 35, except for specific diseases such as hypertrophic cardiomyopathy and idiopathic cardiomyopathy, where a lower cut-off has been suggested. However, nowadays, it is more appropriate to report $V_{\mathrm{E}}^{\prime}$ versus $V^{\prime} \mathrm{CO}_{2}$ slope as percentage of the predicted value, due to age and gender interferences. Relevant attention is needed in $V_{\mathrm{E}}^{\prime}$ versus $V_{\mathrm{CO}_{2}}^{\prime}$ analysis in the presence of heart failure comorbidities. Finally, $V_{\mathrm{E}}^{\prime}$ versus $V_{\mathrm{CO}_{2}}^{\prime}$ abnormalities are relevant targets for treatment in heart failure.

\section{Physiological aspects of the $V^{\prime}{ }_{E}$ versus $V^{\prime}{ }_{\mathrm{CO}_{2}}$ relationship and its association with heart failure prognosis}

During an exercise with a progressively increasing workload, minute ventilation $\left(V_{\mathrm{E}}^{\prime}\right)$ increases in four distinct domains. The first domain is aerobic carbon dioxide production $\left(V^{\prime} \mathrm{CO}_{2}\right)$ in parallel with oxygen

Previous articles in this series: No. 1: Laveneziana P, Di Paolo M, Palange P. The clinical value of cardiopulmonary exercise testing in the modern era. Eur Respir Rev 2021; 30: 200187.

Provenance: Commissioned article, peer reviewed.

Received: 14 May 2020 | Accepted after revision: 21 June 2020

Copyright CERS 2021. This article is open access and distributed under the terms of the Creative Commons Attribution Non-Commercial Licence 4.0. 
uptake $\left(V_{\mathrm{O}_{2}}^{\prime}\right)$ increase, the second is $V^{\prime} \mathrm{CO}_{2}$ anaerobic production with acidosis buffered by the available bicarbonate systems, the third is hydrogen $\left(\mathrm{H}^{+}\right)$when acidosis becomes unbuffered, and the fourth, evident in a few elite athletes, is related to heat dispersion [1,2]. The last, rarely observed in normal subjects, is the main ventilatory drive for furred animals with no or extremely limited sweat production. Hyperventilation due to heat dispersion is known as panting. In dogs, panting is associated with extreme vasodilation of the tongue, while in humans panting is exceeded by thermal dispersion through sweat, so that it seldom becomes the driving force for $V_{E}^{\prime}$, and only at the very end of exercise. According to the different $V_{\mathrm{E}}^{\prime}$ domains, four slopes on the $V_{\mathrm{E}}^{\prime}$ versus workload relationship can be identified in athletes, but only three can be identified in subjects who are not athletes [2, 3] (figure 1). Consequently, up to the respiratory compensation point (RCP), which separates buffered from unbuffered acidosis, the relationship between $V_{\mathrm{E}}^{\prime}$ and $V^{\prime} \mathrm{CO}_{2}$ is linear. The buffering capacity of the body during a short-lasting exercise mainly depends on the amount of bicarbonates available, which in turn strictly relates to pre-exercise $V_{\mathrm{E}}^{\prime}$. In case of voluntary hyperventilation, which usually takes place immediately before and/or in the early phases of exercise, or of hyperventilation related to ambient conditions or to the disease itself, the reduced capacity

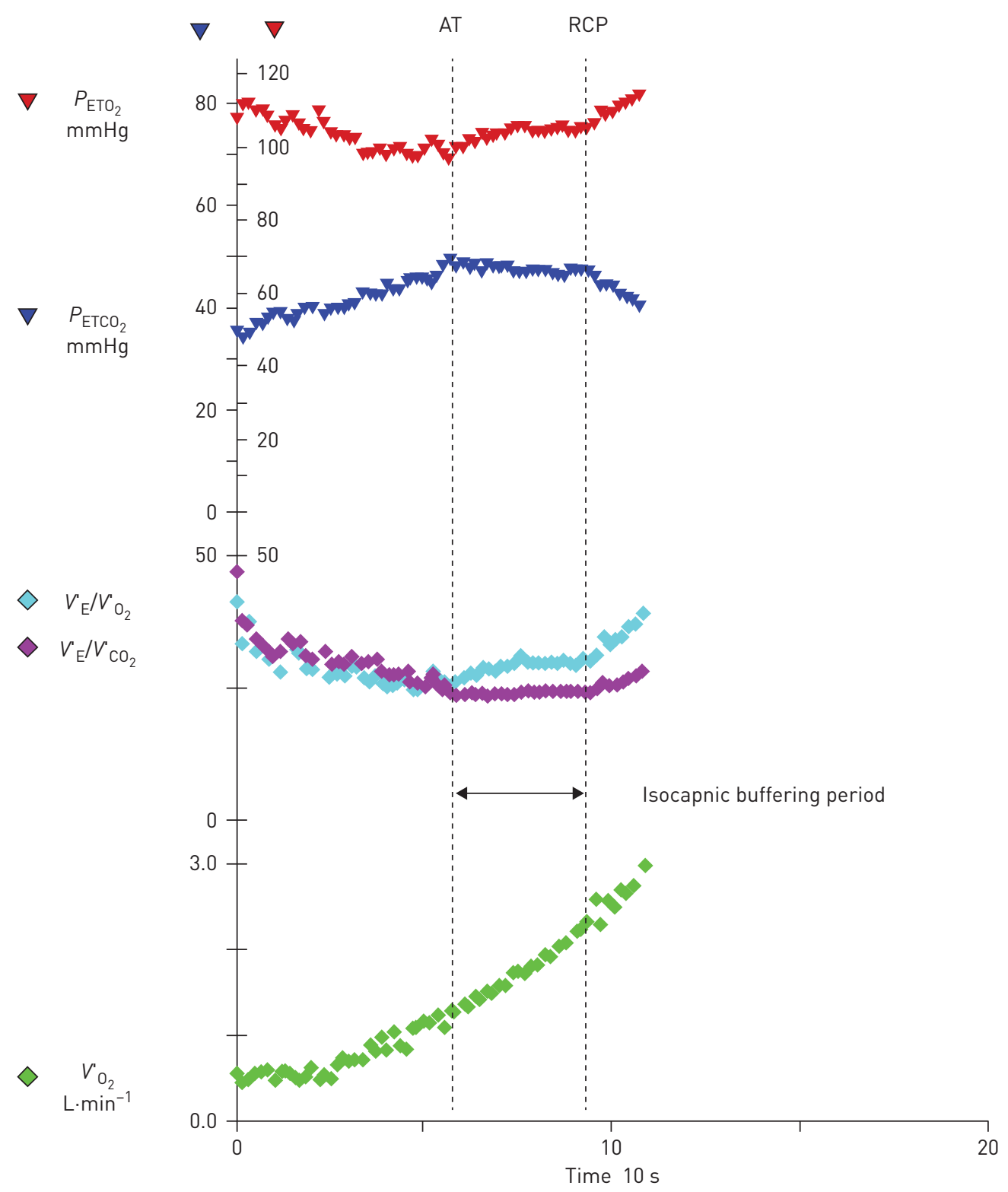

FIGURE 1 A few cardiopulmonary exercise parameters during a ramp exercise protocol. AT: anaerobic threshold; RCP: respiratory compensation point; $P_{\mathrm{ETO}_{2}}$ : end-tidal oxygen pressure; $P_{\mathrm{ETCO}}$ : end-tidal carbon dioxide pressure; $V_{\mathrm{E}}^{\prime}$ : ventilation; $V_{\mathrm{O}_{2}}^{\prime}$ : oxygen uptake; $V^{\prime} \mathrm{CO}_{2}$ : carbon dioxide production. Reproduced from [3] with permission. 
of lactate buffering shortens the length of the isocapnic buffering period and reduces the $V_{\mathrm{O}_{2}}^{\prime}$ therein $[4,5]$. At high altitude, where hypoxia-induced hyperventilation is the norm, the isocapnic buffering period even disappears (figure 2) [6]. Of note, in heart failure, the $V_{\mathrm{O}_{2}}^{\prime}$ increase during the isocapnic buffering period is directly associated with overall exercise performance $[3,7]$.

In heart failure patients, the mere identification of these three ventilation periods during a maximal exercise carries a relevant prognostic power [8]. The lack of identification of the ventilatory thresholds 1 and 2, as defined in the German literature [9], i.e. the anaerobic threshold (AT) and the RCP, respectively, can be due to several causes, such as periodic breathing, erratic breathing, uneven muscle fibre perfusion or metabolism [10]. The nonidentification of AT in an exercise where anaerobic metabolism has been reached, as suggested by a respiratory exchange ratio $\left(V^{\prime} \mathrm{CO}_{2} / V^{\prime} \mathrm{O}_{2}\right)>1.05$, is associated with a poor prognosis [11]. This happens in $\approx 10 \%$ of chronic heart failure patients who perform a maximal or nearly maximal cardiopulmonary exercise testing (CPET) [11]. An intermediate prognosis is that of heart failure patients with an identified AT but an unidentified RCP [8]. Figure 3, derived from the analysis of 1995 heart failure patients belonging to the Metabolic Exercise Cardiac Kidney Index score database, reports the survival of patients with identified AT and RCP (39\% of cases), with identified AT and unidentified RCP (46\% of cases), and with unidentified AT and RCP (15\% of cases). The best prognosis was observed in patients in whom both AT and RCP were identified, whereas the risk of reaching the study end-point

a)
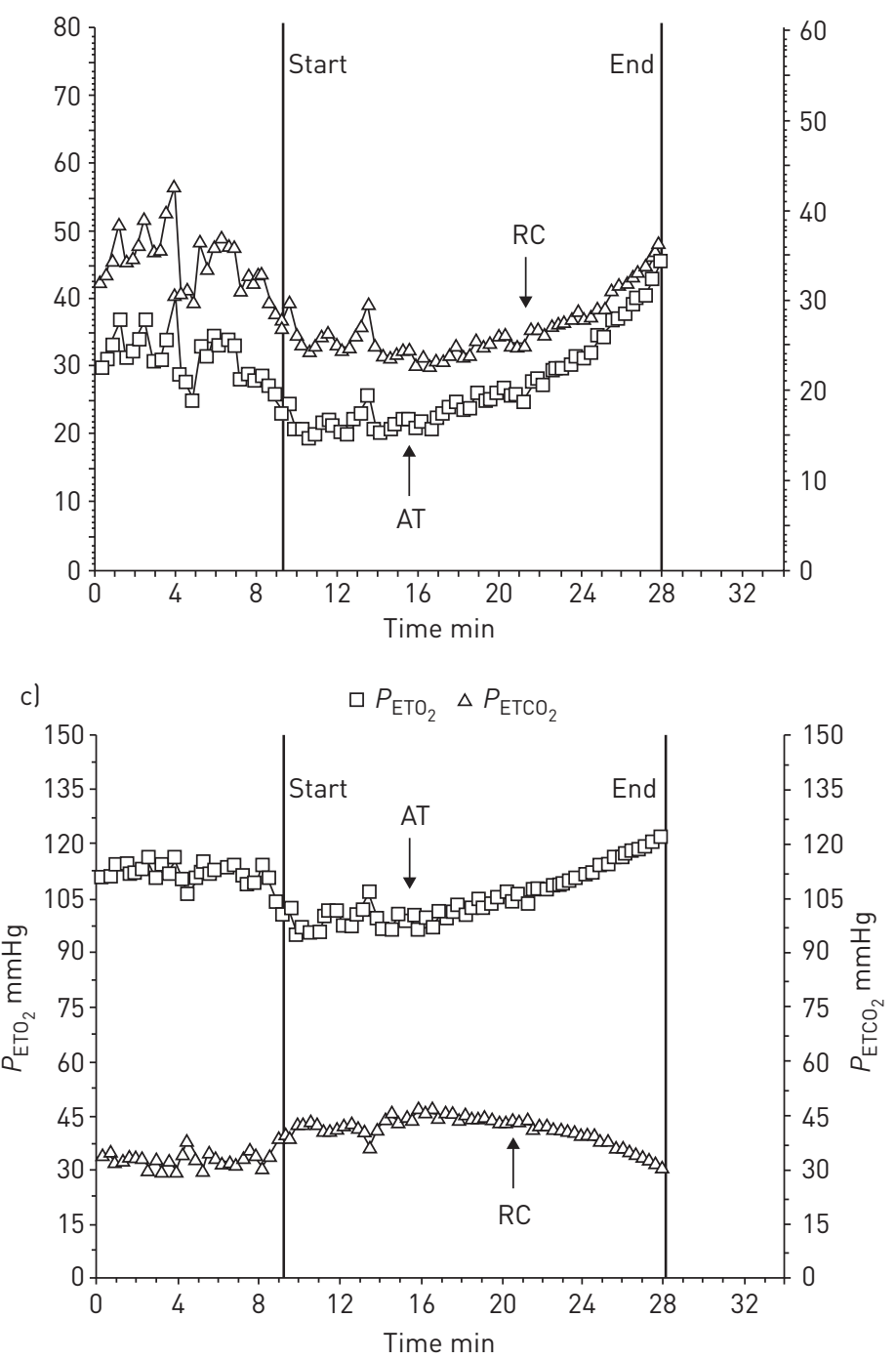

b)

$$
\square V_{E}^{\prime} / V_{\mathrm{O}_{2}}^{\prime} \Delta V^{\prime} / V_{\mathrm{CO}_{2}}^{\prime}
$$

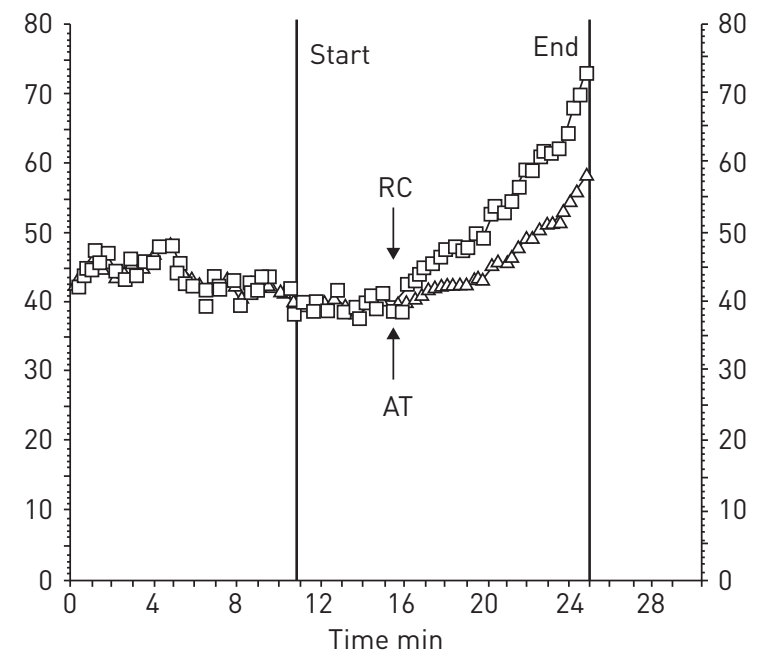

d)

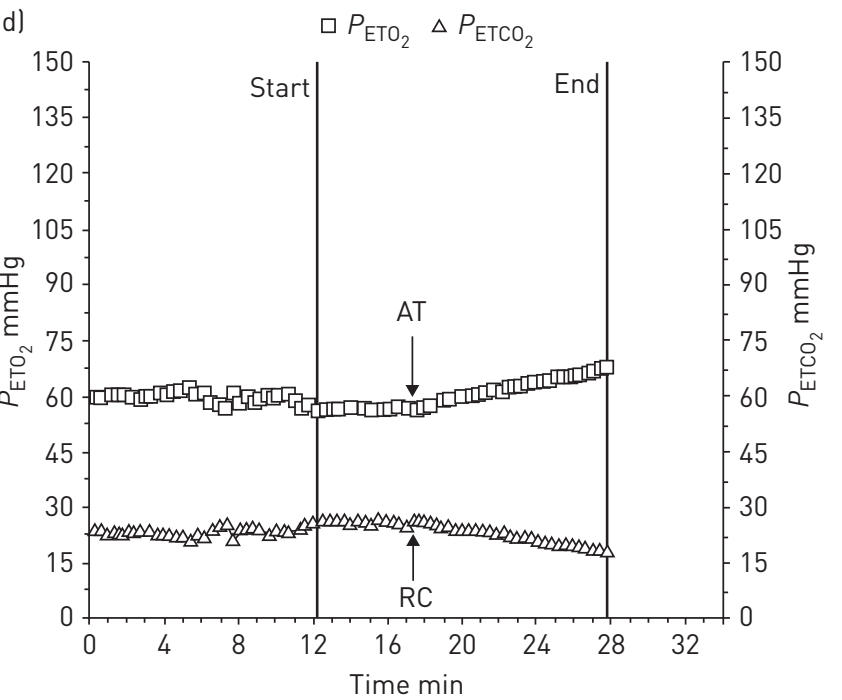

FIGURE 2 Cardiopulmonary exercise parameters during a ramp exercise protocol: oxygen uptake $\left(V^{\prime}{ }_{\mathrm{O}_{2}}\right)$ and carbon dioxide production $\left(V^{\prime} \mathrm{Co}_{2}\right)$ a) at sea level and b) at high altitude (Capanna Regina Margherita, Monte Rosa, Italian Alps, 4559 m) and end-tidal oxygen pressure ( $P_{\mathrm{ETO}_{2}}$ ) and end-tidal carbon dioxide pressure $\left(P_{\mathrm{ETCO}_{2}}\right) \mathrm{C}$ ) at sea level and d) at high altitude. $V^{\prime}{ }_{\mathrm{E}}$ : ventilation; RC: respiratory compensation point; AT: anaerobic threshold. Reproduced from [6] with permission. 


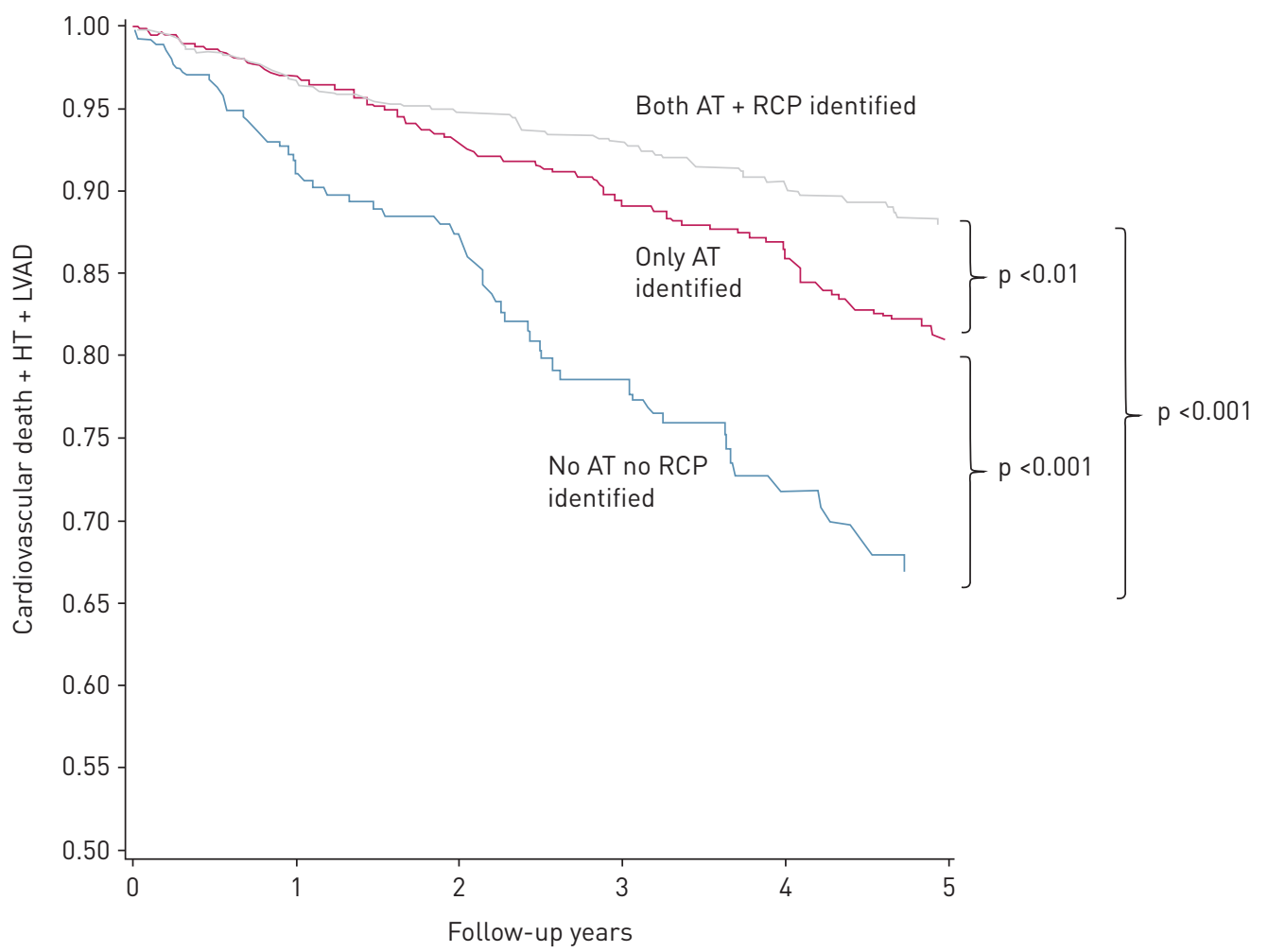

FIGURE 3 5-year survival analysis in heart failure patients in whom anaerobic threshold (AT) and respiratory compensation point (RCP) were not identified ( $n=292)$, in whom only AT was identified $(n=920)$ and in whom both AT and RCP $(n=783)$ were identified. HT: heart transplant; LVAD: left ventricular assist device. Reproduced from [8] with permission.

(composite of cardiovascular death, urgent heart transplant or left ventricular assist device) increased by 1.4 times in patients with AT but not RCP, and by 2.7 times in patients in whom neither AT nor RCP were identified [8]. Of note, the prognostic power of the identification of the aforementioned thresholds is independent of the $V^{\prime} \mathrm{O}_{2}$ value reached at the threshold. Thus, as regards heart failure patients' survival, any AT $V^{\prime} \mathrm{O}_{2}$ value, albeit very low, is better than an unidentified AT [11].

Ventilation is the sum of alveolar $\left(V_{\mathrm{A}}^{\prime}\right)$ and dead space $\left(V_{\mathrm{D}}^{\prime}\right)$ ventilation, which is the part of $V_{\mathrm{E}}^{\prime}$ that does not participate in gas exchange. In normal subjects, $V_{\text {A }}^{\prime}$ progressively increases during exercise, while $V_{\mathrm{D}}^{\prime}$ decreases, so that the linear relationship between $V_{\mathrm{E}}^{\prime}$ and $V_{\mathrm{CO}_{2}}^{\prime}$ has a positive intercept on the $V_{\mathrm{E}}^{\prime}$ axis, i.e. the extrapolation of $V_{\mathrm{E}}^{\prime}$ at $V_{\mathrm{CO}_{2}}^{\prime}=0$ (figure 4) [12]. Above RCP, $V_{\mathrm{E}}^{\prime}$ increase is mainly due to respiratory rate increase, with a minimal further increase in tidal volume. During exercise, the end-expiratory $\mathrm{CO}_{2}$ pressure $\left(P_{\mathrm{ETCO}_{2}}\right)$ increases up to the isocapnic buffering period, when its highest value is reached. In normal subjects, both $P_{\mathrm{ETCO}}$ and arterial $\mathrm{CO}_{2}$ pressure $\left(P_{\mathrm{aCO}}\right)$ remain within their normal ranges up to RCP, but, above it, both $P_{\mathrm{aCO}_{2}}$ and $P_{\mathrm{ETCO}_{2}}$ decrease $[10,13]$. Accordingly, during exercise, if $P_{\mathrm{ETCO}_{2}}$ is low but $P_{\mathrm{aCO}}$ is in the normal range, $V_{\mathrm{D}}^{\prime}$ must be increased due to $V_{\mathrm{E}}^{\prime} /$ perfusion $\left(Q^{\prime}\right)$ mismatch, with a prevalence of ventilated but not perfused lung zones. Differently, if $P_{\mathrm{aCO}}$ is low, the increase in $V_{\mathrm{E}}^{\prime}$ is due to other stimuli such as reflexes (chemo-, metaboreflexes), so that the observed $V_{\mathrm{E}}^{\prime} / Q^{\prime}$ mismatch is a consequence and not a cause of hyperventilation. These two types of $V_{\mathrm{E}}^{\prime}$ increase have different denominations: hyperpnoea when $P_{\mathrm{aCO}}$ is in its normal range, and hyperventilation when $P_{\mathrm{aCO}_{2}}$ is low [14-16.] Experimentally, during exercise, a fixed increase in $V_{\mathrm{D}}^{\prime}$ is associated with an upward shift of the $V_{\mathrm{E}}^{\prime}$ versus $V_{\mathrm{CO}_{2}}^{\prime}$ relationship, whereas a progressive increase in $V_{\mathrm{D}}^{\prime}$ during exercise generates an increased $V_{\mathrm{E}}^{\prime}$ versus $V^{\prime} \mathrm{CO}_{2}$ relationship slope (figure 4) $[12,17]$. In brief, in normal subjects, the $V_{\mathrm{E}}^{\prime}$ versus $V^{\prime} \mathrm{CO}_{2}$ relationship slope increase is linear up to $\mathrm{RCP}$, with a positive $\mathrm{Y}$-axis $\left(V_{\mathrm{E}}^{\prime}\right.$ axis) intercept. Remarkably, the Y-axis intercept is not an indicator of $V^{\prime}{ }_{\mathrm{D}}$ unless it has been added externally, but it provides information about $V_{D}^{\prime}$ changes during exercise $[18,19]$. The role of Y-axis intercept evaluation in specific comorbidities such as COPD/pulmonary arterial hypertension are discussed in detail later.

Finally, the analysis of the last part of exercise, i.e. the part above RCP, provides useful information. Indeed, when a further increase in the slope of the $V_{\mathrm{E}}^{\prime}$ versus $V^{\prime} \mathrm{CO}_{2}$ relationship slope is observed, then the increase of $V_{\mathrm{E}}^{\prime}$ is only due to an increase of respiratory rate, so that $V_{\mathrm{D}}^{\prime}$ increases, but no or very limited increase of $V_{\mathrm{A}}^{\prime}$ is present [20]. In these cases, the $P_{\mathrm{ETCO}_{2}}-P_{\mathrm{aCO}_{2}}$ difference becomes significantly 

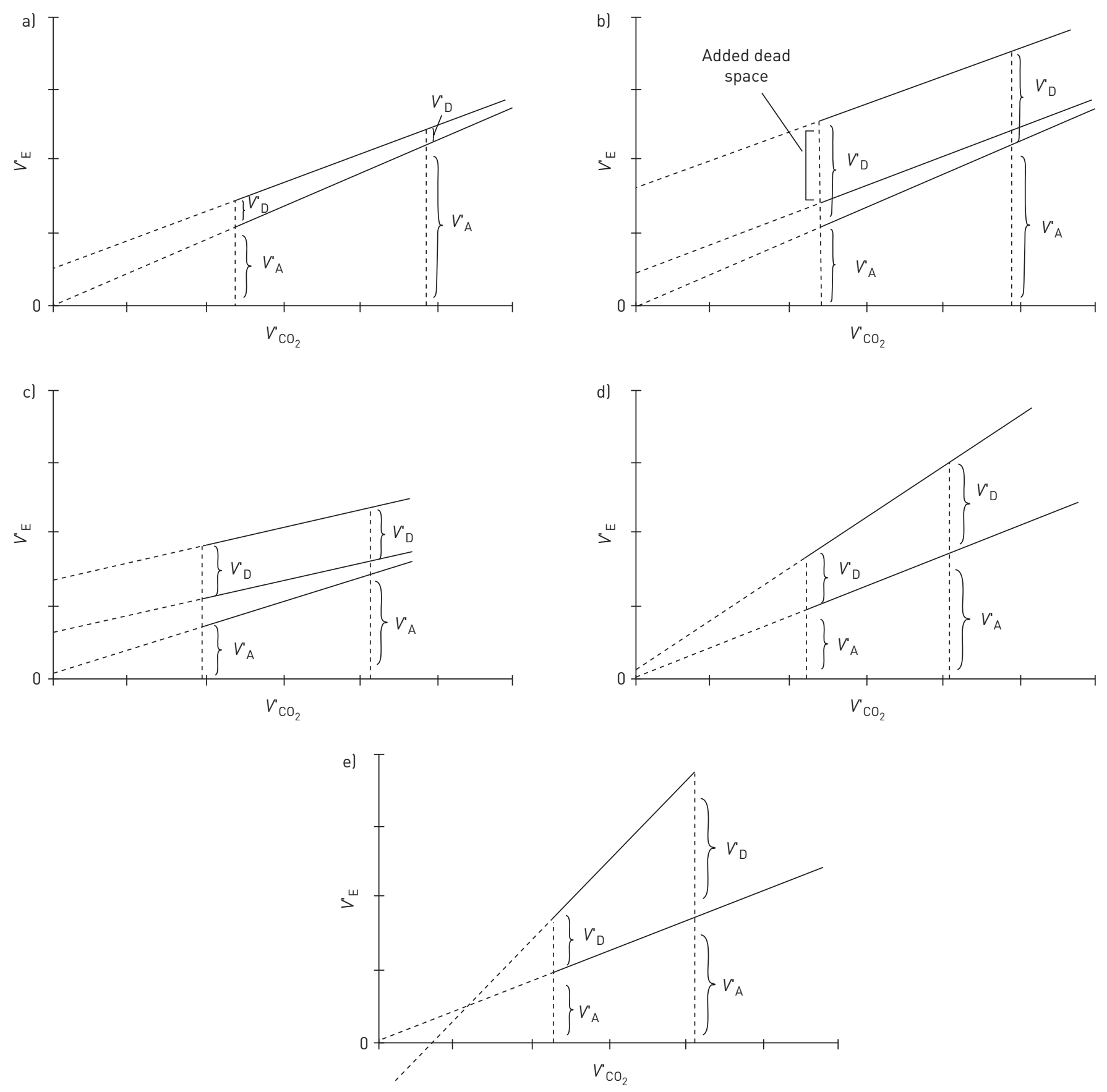

FIGURE 4 Schematic representation of ventilation $\left(V_{E}^{\prime}\right)$ and carbon dioxide changes $\left(V^{\prime} \mathrm{CO}_{2}\right)$ during exercise in five different conditions: a) normal subject; b) normal subject with added external dead space; c) COPD; d) heart failure; e) pulmonary arterial hypertension. Dead space ( $\left.V^{\prime}{ }_{D}\right)$ and alveolar $\left(V^{\prime}\right)$ ventilation are also reported. Reproduced from [12] with permission.

negative. As a matter of fact, in parallel with the study of the $V_{\mathrm{E}}^{\prime}$ versus $V^{\prime} \mathrm{CO}_{2}$ relationship, both as slope and as Y-intercept, attention must be dedicated to $P_{\mathrm{ETCO}_{2},} P_{\mathrm{aCO}_{2}}$ and $P_{\mathrm{ETCO}_{2}}-P_{\mathrm{aCO}_{2}}$ difference during workload increase, because, combined, they provide us with clear information about $V_{\mathrm{D}}^{\prime}$ changes and $V_{\mathrm{E}}^{\prime} / Q^{\prime}$ mismatch during exercise.

How to report the $V^{\prime}$ versus $V^{\prime} \mathrm{CO}_{2}$ relationship

The relationship between $V_{\mathrm{E}}^{\prime}$ and $V^{\prime} \mathrm{CO}_{2}$ can be reported as the ratio or as the exercise relationship slope, but it used to be reported as $V_{\mathrm{E}}^{\prime}$ at $V_{\mathrm{CO} 2}^{\prime}=1 \mathrm{~L} \cdot \mathrm{m}^{-1}$. In normal subjects, the $V_{\mathrm{E}}^{\prime} / V^{\prime} \mathrm{CO}_{2}$ ratio decreases at the beginning of exercise, then stays still and increases above RCP, reproducing a characteristic $U$ shape (figure 5). However, several shapes of the $V_{\mathrm{E}}^{\prime} / V^{\prime} \mathrm{CO}_{2}$ ratio can be observed in specific clinical conditions, 
and looking at the shape can provide useful information, as follows. 1) In case of pre-test hyperventilation, the $V_{\mathrm{E}}^{\prime} / V^{\prime} \mathrm{CO} 2$ ratio progressively declines during exercise; 2) in $\mathrm{COPD}$, the $V_{\mathrm{E}}^{\prime} / V_{\mathrm{CO} 2}^{\prime}$ ratio is high and stays still or shows a limited reduction during exercise; 3) in case of heart failure, the $V_{\mathrm{E}}^{\prime} / V^{\prime} \mathrm{CO}_{2}$ ratio shifts upward, but usually maintains its $U$ shape; 4 ) in case of pulmonary hypertension, $V_{E}^{\prime} / V^{\prime} \mathrm{CO}_{2}$ ratio values are elevated and steady or progressively increasing in relation to the severity of pulmonary hypertension. The $V_{\mathrm{E}}^{\prime} / V^{\prime} \mathrm{CO}_{2}$ ratio has been reported at various moments of exercise, including submaximal and peak exercise [21-23.] The less variable $V_{\mathrm{E}}^{\prime} / V^{\prime} \mathrm{CO}_{2}$ ratio is probably the lowest recorded in a ramp exercise protocol, and it has been suggested as the value to consider as more clinically relevant [24-26.] In an exercise with a progressively increasing workload, the so-called ramp protocol test, the $V_{\mathrm{E}}^{\prime}$ versus $V^{\prime} \mathrm{CO}_{2}$ relationship slope is physiologically measured from the beginning of exercise, usually after 1 min to avoid alteration of $V_{\mathrm{E}}^{\prime}$ associated with patients' adaptation to exercise, up to the RCP, above which a second slope of the $V_{\mathrm{E}}^{\prime}$ versus $V^{\prime} \mathrm{CO}_{2}$ relationship is usually present. In some laboratories, the $V_{\mathrm{E}}^{\prime}$ versus $V^{\prime} \mathrm{CO}_{2}$ slope is assessed throughout the exercise, and it is consequently a little bit higher, although, when doing so, the clinical significance of the Y-axis intercept becomes at least less clear, if not lost [27, 28]. However, it is likely that both analyses can be accepted, provided that the CPET report clearly states which method has been applied, since reference values are probably different. Both the $V_{\mathrm{E}}^{\prime} / V_{\mathrm{CO}_{2}}^{\prime}$ ratio and the $V_{\mathrm{E}}^{\prime}$ versus $V^{\prime} \mathrm{CO}_{2}$ relationship slope (plus its $\mathrm{Y}$-axis intercept) must be assessed in heart failure patients. Indeed, in parallel with the $P_{\mathrm{ETCO}_{2}}$ value, the $V_{\mathrm{E}}^{\prime} / V^{\prime} \mathrm{CO}_{2}$ ratio value during the isocapnic buffering period, when it is flat, gives information on the activation of the ventilation reflex [13], while the relationship slope tells more directly about the efficiency of $V_{\mathrm{E}}^{\prime}$ during exercise and the development of $V_{\mathrm{D}}^{\prime}$.

Normal values of the slope of the $V^{\prime}{ }_{E}$ versus $V^{\prime}{ }_{\mathrm{CO}_{2}}$ relationship and of $V^{\prime}{ }_{E} / V^{\prime} \mathrm{CO}_{2}$ ratio Sex- and age-specific normal values of the $V^{\prime}{ }_{\mathrm{E}} / V^{\prime} \mathrm{CO}_{2}$ ratio, both at AT and as the lowest value, of $V^{\prime} \mathrm{E}$ versus $V^{\prime} \mathrm{CO}_{2}$ relationship slope and Y-axis intercept for normal subjects have been reported by SuN et al. [24], with a lowest $V^{\prime}{ }_{\mathrm{E}} / V^{\prime} \mathrm{CO}_{2}$ cut-off value for poor prognosis $\geqslant 33$ [25]. Differently, the normal values of the $V_{\mathrm{E}}^{\prime}$ versus $V_{\mathrm{CO}_{2}}^{\prime}$ relationship slope have been placed by several authors below an arbitrary value of 35 , assuming that there is no influence of sex and age [29-32.] This arbitrary, "good-for-all" cut-off value has been proposed in different studies and even in guidelines [33], although the $V_{\mathrm{E}}^{\prime}$ versus $V^{\prime} \mathrm{CO}_{2}$ slope increases with age and is higher in females [29]. In their pioneering work, KLEBER et al. [34] utilised a percentage of predicted value to define the prognostic power of the $V_{\mathrm{E}}^{\prime}$ versus $V_{\mathrm{CO}_{2}}^{\prime}$ slope in heart failure. However, the normal population was small $(n=101)$ and included 56 females. Similarly, other
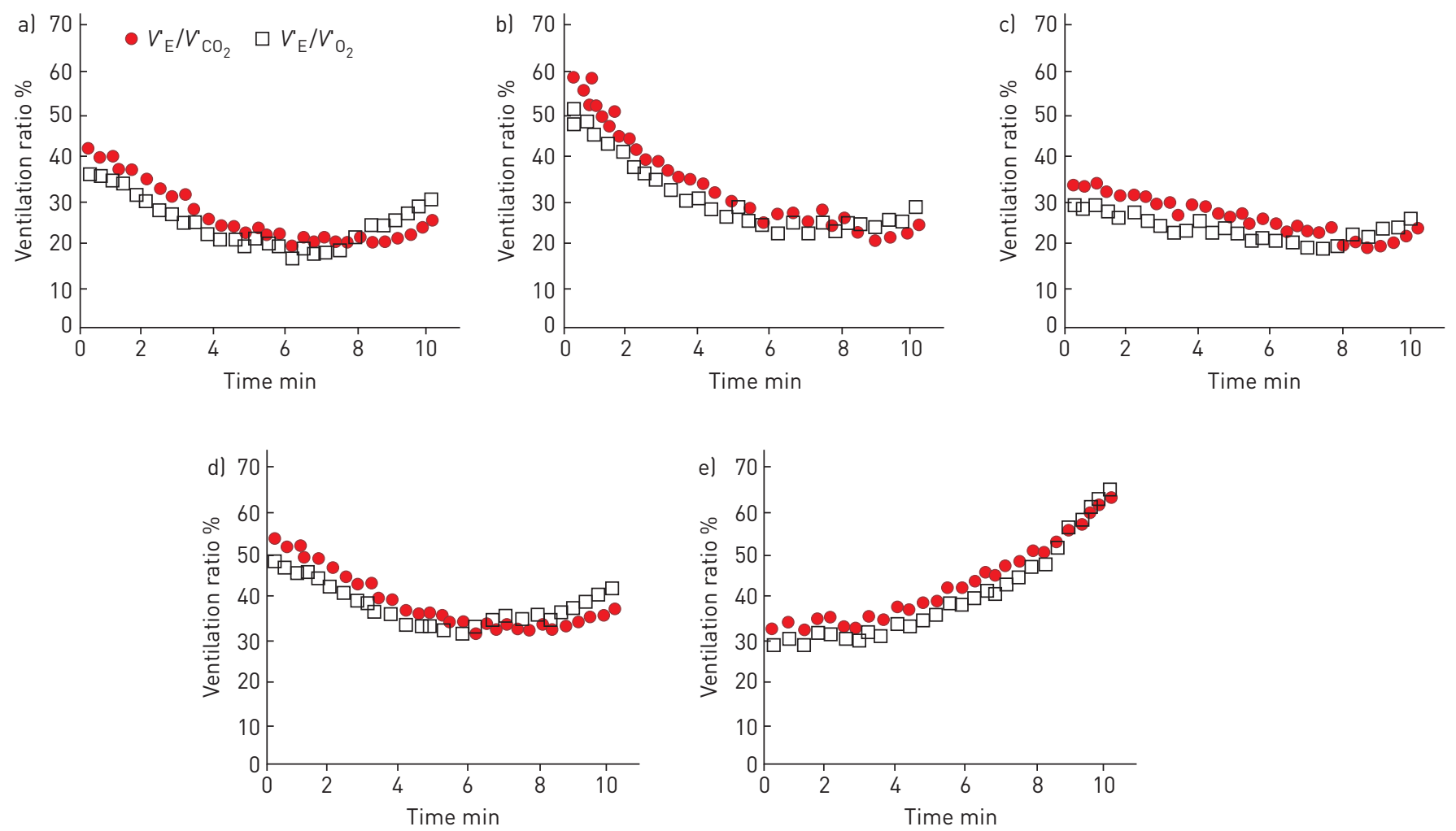

FIGURE 5 Minute ventilation $\left(V_{E}^{\prime}\right)$ /oxygen uptake $\left(V_{O_{2}}^{\prime}\right)$ and $V^{\prime}$ /carbon dioxide production $\left(V^{\prime} \mathrm{CO}_{2}\right)$ ratio behaviour in a ramp exercise protocol in a) normal subjects; b) in case of pre-test hyperventilation; c) in COPD; d) in heart failure; and e) in pulmonary arterial hypertension. 
normal-value equations were proposed $[24,35,36]$ but all from small samples, except very recently, when SALVioni et al. [29] reported normal values of a large population of both genders and all ages. Figure 6 [29] shows the regression equations of $V_{\mathrm{E}}^{\prime}$ versus $V_{\mathrm{CO}_{2}}^{\prime}$ slope relationship obtained in 1136 normal subjects (773 males and 363 females). The available regression equations to calculate the percentage of predicted $V^{\prime}{ }_{\mathrm{E}} / V^{\prime} \mathrm{CO}_{2}$ slope are reported in table 1 [29]. Most importantly, SALVIONI et al. [29] demonstrated that the percentage of $V_{\mathrm{E}}^{\prime}$ versus $V_{\mathrm{CO}_{2}}^{\prime}$ slope enhances the prognostic capacity of $V_{\mathrm{E}}^{\prime}$ versus $V_{\mathrm{CO}_{2}}^{\prime}$ slope in patients with severe heart failure (peak $V_{\mathrm{O}_{2}}^{\prime}<14 \mathrm{~mL} \cdot \mathrm{min}^{-1} \cdot \mathrm{kg}^{-1}$ ), who are more in need of a precise life expectancy estimation.
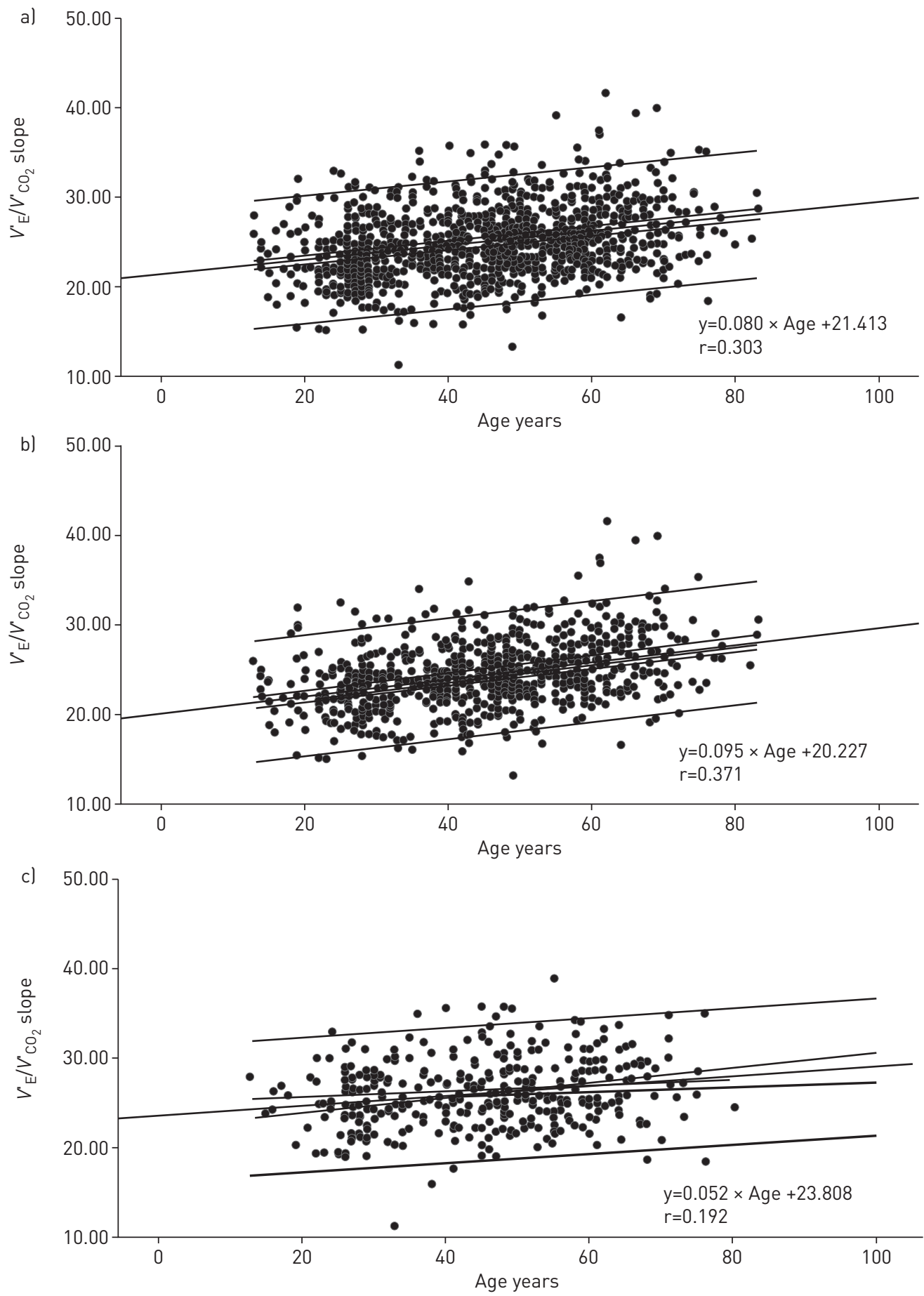

FIGURE 6 Linear regression between minute ventilation $\left(V^{\prime}{ }_{E}\right) /$ carbon dioxide production $\left(V^{\prime} \mathrm{CO}_{2}\right)$ slope and age in a) normal subjects $(n=1136)$; b) males $(n=773)$; and c) females $(n=363)$. Reproduced from [29] with permission. 
TABLE 1 Regressions proposed to calculate predicted ventilation/carbon dioxide production slope

\section{First author, year (study)}

[reference]

Subjects (male/female)

Males

Females

Age years

Ergometer

SALVIONI, 2020 [29]

КосH, 2009 (SHIP) [35]

KLeber, 2000 [34]

Neder, 2001 [36]

PouLIN, 1994 [37]

Sun, 2002 [24]

$1136(773 / 363)$
$534(253 / 281)$

$101(45 / 56)$
$120(60 / 60)$
$224(128 / 96)$
$474(310 / 164)$

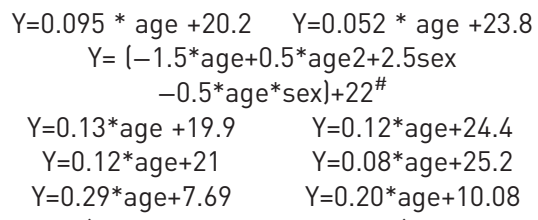

$\begin{array}{cc}13-83 & \text { Cycle ergometer } \\ \text { 25-80 } & \text { Cycle ergometer } \\ & \\ 16-75 & \text { Treadmill } \\ 20-80 & \text { Cycle ergometer } \\ 55-86 & \text { Treadmill } \\ 37-74 & \text { Cycle ergometer/Treadmill }\end{array}$

$13-83$

$16-75$

$55-86$

$37-74$

Cycle ergometer/ Treadmill

Data are presented as $\mathrm{n}$ or range, unless otherwise stated. Reproduced and modified from [29] with permission. " : age was graded in five classes $(25-34,35-44,45-54,55-64$ and $\geqslant 65$ years) and coded for the calculation.

\section{Mechanical and pharmacological manipulation of the $V^{\prime}{ }_{\mathrm{E}}$ versus $V^{\prime} \mathrm{CO}_{2}$ relationship}

The $V_{\mathrm{E}}^{\prime}$ versus $V^{\prime} \mathrm{CO}_{2}$ slope was assessed after a few manipulation manoeuvres. As mentioned earlier, an increase in external $V_{D}^{\prime}$ shifts the $V_{\mathrm{E}}^{\prime}$ versus $V^{\prime} \mathrm{CO}_{2}$ relationship upward, but it does not affect the slope [18]. Differently, in normal volunteers, shortly after an acute saline infusion at a rate allowing an infusion ranging between 25 and $30 \mathrm{~mL} \cdot \mathrm{kg}^{-1}$ in $<30 \mathrm{~min}$, a significant $(\approx 12 \%)$ increase of $V_{\mathrm{E}}^{\prime}$ versus $V^{\prime} \mathrm{CO}_{2}$ relationship slope was observed [38, 39]. Noteworthy, when alveolar-capillary membrane fluid movement is hampered by alveolar $\beta_{2}$-receptor blockade, i.e. when active absorption of fluids from the alveolar space is impeded [40,41], the $V_{\mathrm{E}}^{\prime}$ versus $V^{\prime} \mathrm{CO}_{2}$ slope increase is $\sim 10 \%$, with a further increase when rapid saline infusion and alveolar $\beta_{2}$-receptor blockade are combined [39]. Altogether, these data suggest a direct relationship between lung stiffness generated by an increased lung fluid content and $V_{E}^{\prime}$ inefficiency [42].

Reflex-mediated (metabo- and chemoreflex) increase in $V_{\mathrm{E}}^{\prime}$ is also associated with a $V_{\mathrm{E}}^{\prime}$ versus $V^{\prime} \mathrm{CO}_{2}$ slope increase. This phenomenon was shown in exercises performed during acute high-altitude exposure, i.e. with hypobaric hypoxia [43-46.] Conversely, at a simulated altitude of $2000 \mathrm{~m}$, the $V_{\mathrm{E}}^{\prime}$ versus $V_{\mathrm{CO}_{2}}^{\prime}$ slope increases in heart failure patients. Interestingly, carvedilol in the same laboratory conditions significantly reduces the slope from $39 \pm 10$ to $32 \pm 14$, most likely because of a reduction of chemoreceptor stimulation by hypoxia through $\beta_{1^{-}}, \beta_{2^{-}}$and $\alpha$-receptor blockade [47].

The relationship between $V_{\mathrm{E}}^{\prime}$ and $V^{\prime} \mathrm{CO}_{2}$, either measured as the ratio or as the relationship slope, is high in heart failure. There are several possible causes, including abnormal increased lung stiffness due to interstitial pulmonary alterations (increased intrathoracic fluids, fibrosis, etc.), increased chemo- and metaboreflex sensitivity, early metabolic acidosis and abnormal pulmonary haemodynamics with secondary pulmonary hypertension and high pulmonary wedge pressure. The combination of all the above mechanisms lead to $V_{\mathrm{E}}^{\prime} / Q^{\prime}$ mismatch, so that, for a given $V_{\mathrm{CO}_{2}}^{\prime}, V_{\mathrm{E}}^{\prime}$ is increased. In heart failure, the elevated $V_{\mathrm{E}}^{\prime}$ versus $V^{\prime} \mathrm{CO}_{2}$ relationship is associated with a low $P_{\mathrm{ETCO}_{2}}$, which should be analysed mainly during the isocapnic buffering period (between AT and RCP) when $P_{\mathrm{ETCO}_{2}}$ most directly mirrors reflex activity [13]. In a pioneering, large, multicentre study on $V_{\mathrm{E}}^{\prime}$ abnormalities in heart failure, WASSERMAN et al. [48] showed that, in heart failure patients, $8 \%, 47 \%$ and $45 \%$ of $V_{\mathrm{E}}^{\prime}$ increase is due to $P_{\mathrm{aCO}_{2}}, V^{\prime} \mathrm{CO}_{2}$ and $V_{\mathrm{D}}^{\prime}$ volume $\left(V_{\mathrm{D}}\right) /$ tidal volume $\left(V_{\mathrm{T}}\right)$ ratio, respectively. More recently, MezzANi et al. [49] documented that the overactivation of reflex response is the main cause of the observed increase of $V^{\prime}{ }_{E} / V^{\prime} \mathrm{CO}_{2}$, while haemodynamic impairment plays an additional role in more advanced stages of heart failure. As regards the comparison between heart failure patients with preserved and with reduced ejection fraction, VAN ITERSON et al. [17] showed during exercise an impaired $V_{\mathrm{E}}^{\prime}$ efficiency in both groups, despite a higher $V_{\mathrm{E}}^{\prime}$ versus $V_{\mathrm{CO}_{2}}^{\prime}$ slope value in those with reduced ejection fraction as well as a different $P_{\mathrm{aCO}}$ and $V_{\mathrm{D}} / V_{\mathrm{T}}$ behaviour. Indeed, in heart failure patients with preserved ejection fraction, hyperpnoea, i.e. low $V_{\mathrm{D}} / V_{\mathrm{T}}$ and normal $P_{\mathrm{aCO}_{2}}$, seems to be the most prevalent cause of $V_{\mathrm{E}}^{\prime}$ increase, whereas in those with reduced ejection fraction, hyperventilation, i.e. overactivated reflexes and low $P_{\mathrm{aCO}}$, seems to be the main cause of the increase of $V_{E}^{\prime}[17,50]$. It must be underlined that heart failure patients with preserved ejection fraction actually suffer from a hodgepodge of different diseases, so that averaging data may be misleading. Several reports have shown the relevant role of $V_{\mathrm{E}}^{\prime}$ versus $V_{\mathrm{CO}_{2}}^{\prime}$ relationship in heart failure prognosis [22, 34, 51-60] with an average cut-off value of 35 [61]. Indeed, a classification of heart failure severity based on $V_{\mathrm{E}}^{\prime}$ versus $V_{\mathrm{CO}_{2}}^{\prime}$ slope has been suggested [62] and reported in heart failure guidelines [33]. Several heart failure prognostic scores include CPET data [63-71]. Notably, $V^{\prime}{ }_{\mathrm{E}}$ versus $V^{\prime} \mathrm{CO}_{2}$ slope maintains its strong prognostic role, even in composite heart failure scores [64, 65, 68]. In heart failure, a strong correlation has been described between $V^{\prime}$ E versus $V_{\mathrm{CO}_{2}}^{\prime}$ relationship abnormalities and sleep apnoea, 
which also has a relevant prognostic power in heart failure $[72,73]$. Of note, the $V_{\mathrm{E}}^{\prime}$ versus $V^{\prime} \mathrm{CO}_{2}$ relationship during exercise, regardless of how it is measured, has a relevant prognostic power both in heart failure patients with preserved and reduced ejection fraction, albeit stronger in the former [74]. Finally, the prognostic meaning of specific $V_{\mathrm{E}}^{\prime}$ versus $V^{\prime} \mathrm{CO}_{2}$ slope values must be evaluated considering patients' age, date of CPET and healthcare situation. Indeed, the $V_{\mathrm{E}}^{\prime}$ versus $V^{\prime} \mathrm{CO}_{2}$ slope was reported to be higher in elderly patients [75], while for CPETs performed in 1993-2000, 2000-2005, 2005-2010 and 2010-2015, for a $V_{\mathrm{E}}^{\prime}$ versus $V^{\prime} \mathrm{CO}_{2}$ of 34, a progressive reduction of the risk of the composite event cardiovascular death, urgent heart transplant or left ventricular assist device at 2 years was observed from $\approx 20 \%$, to $\approx 12 \%$, to $\approx 8 \%$ and $\approx 8 \%$, respectively [76]. Therefore, in chronic heart failure patients, the prognostic meaning of the $V_{\mathrm{E}}^{\prime}$ versus $V^{\prime} \mathrm{CO}_{2}$ relationship slope must be contextualised for the current local healthcare situation. This is relevant when comparing previous and present survival results as well as studies done in countries with different access to healthcare facilities.

\section{$V^{\prime}$ E versus $V^{\prime} \mathrm{CO}_{2}$ relationship in heart failure therapy}

Drugs used for heart failure treatment directly influence the $V_{\mathrm{E}}^{\prime}$ versus $V_{\mathrm{CO}_{2}}^{\prime}$ relationship [77]. Specifically, angiotensin-converting enzyme (ACE) inhibitors, but not angiotensin receptor blockers, improve both alveolar-capillary membrane diffusion and $V_{\mathrm{E}}^{\prime}$ versus $V_{\mathrm{CO}_{2}}^{\prime}$ relationship $[78,79]$, but the $V_{\mathrm{E}}^{\prime}$ versus $V^{\prime} \mathrm{CO}_{2}$ slope improvement associated with ACE inhibitors is counteracted by the concomitant use of aspirin [78]. Accordingly, it has been suggested that the ACE inhibitor-induced $V_{\mathrm{E}}^{\prime}$ versus $V^{\prime} \mathrm{CO}_{2}$ slope reduction is mediated by lung stiffness and $V_{\mathrm{D}} / V_{\mathrm{T}}$ reduction, leading to $V_{\mathrm{E}^{\prime}}^{\prime} / Q^{\prime}$ improvement. Like ACE inhibitors, the long-term use of mineral receptor inhibitors, such as spironolactone or eplerenone, improves alveolarcapillary membrane diffusion and exercise performance. However, mineral receptor inhibitors do not seem to affect the $V_{\mathrm{E}}^{\prime}$ versus $V^{\prime} \mathrm{CO}_{2}$ relationship, casting doubts about the true mechanisms of the action of ACE inhibitors on the $V_{\mathrm{E}}^{\prime}$ versus $V^{\prime} \mathrm{CO}_{2}$ relationship [80]. In this regard, a modulating role of ACE inhibitors on chemoreflex activity has been suggested [81]. In addition, $\beta$-blockers can affect the $V_{\mathrm{E}}^{\prime}$ versus $V^{\prime} \mathrm{CO}_{2}$ relationship in heart failure, although this effect is more evident with $\beta_{1}-\beta_{2}$-blockers such as carvedilol [77, $82,83]$. The mechanism is a direct reduction of overactivated chemoreflexes partially counteracted by a worsening of the alveolar-capillary membrane diffusion capacity [13, 39, 84]. Of note, although the reduction of $V_{E}^{\prime}$ response to chemoreflex stimuli is considered a beneficial effect, it may turn into a negative one under specific circumstances such as acute hypoxia [47, 77]. It has been reported that long term sacubitril-valsartan treatment reduces the $V_{\mathrm{E}}^{\prime}$ versus $V_{\mathrm{CO}_{2}}^{\prime}$ slope, but only in patients with a $V_{\mathrm{E}}^{\prime}$ versus $V^{\prime} \mathrm{CO}_{2}$ value $>34$ [85].

\section{$V^{\prime}$ E versus $V^{\prime} \mathrm{CO}_{2}$ relationship in specific aetiologies}

The $V_{\mathrm{E}}^{\prime}$ versus $V_{\mathrm{CO}_{2}}^{\prime}$ relationship during exercise has been studied in specific disease settings of heart failure such as hypertrophic cardiomyopathy, idiopathic cardiomyopathy and cardiac amyloidosis. In patients with hypertrophic cardiomyopathy, the $V_{\mathrm{E}}^{\prime}$ versus $V_{\mathrm{CO}_{2}}^{\prime}$ relationship is usually preserved within normal values. Nonetheless, the occasional finding of an elevated $V_{\mathrm{E}}^{\prime}$ versus $V^{\prime} \mathrm{CO}_{2}$ slope value in hypertrophic cardiomyopathy patients has been associated with severe diastolic dysfunction and secondary pulmonary hypertension $[86,87]$. In hypertrophic cardiomyopathy patients, a $V_{\mathrm{E}}^{\prime}$ versus $V^{\prime} \mathrm{CO}_{2}$ slope value $>32$ has been reported as a powerful predictor of heart failure related events, and it is associated with poor prognosis and sudden cardiac death [88-90]. Of note, an even lower $V_{\mathrm{E}}^{\prime}$ versus $V^{\prime} \mathrm{CO}_{2}$ slope cut-off value, 29, has been suggested by SINAGRA et al. [91] for patients with idiopathic cardiomyopathy. The reason for the low cut-off values is probably that, in both hypertrophic cardiomyopathy and idiopathic cardiomyopathy, there is a high incidence of young patients and male sex. Conversely, in patients with heart failure due to amyloidosis, the $V_{\mathrm{E}}^{\prime}$ versus $V^{\prime} \mathrm{CO}_{2}$ slope is significantly elevated and much more than in other patients with heart failure due to diastolic dysfunction of other origins [92]. The causes of the elevated $V_{\mathrm{E}}^{\prime}$ versus $V^{\prime} \mathrm{CO}_{2}$ slope in these patients is likely the increase of backward pulmonary pressure. In amyloidosis, $V_{\mathrm{E}}^{\prime}$ versus $V_{\mathrm{CO}_{2}}^{\prime}$ relationship is both an indicator of therapy efficacy and a strong independent prognostic marker [92]. Specifically, the combination of $V_{\mathrm{E}}^{\prime}$ versus $V_{\mathrm{CO}_{2}}^{\prime}$ slope, C-reactive protein, sodium plasma level and serum creatinine, all independent significant prognostic indicators, leads to an AUC of 0.89 for 1-year mortality [92].

\section{$V^{\prime}$ E versus $V^{\prime} \mathrm{CO}_{2}$ relationship in heart failure and associated comorbidities}

In some comorbidities the Y-intercept of the $V_{\mathrm{E}}^{\prime}$ versus $V_{\mathrm{CO}_{2}}^{\prime}$ relationship has a central role in the interpretation of diagnosis. If it is above its upper normal value $(2.7 \mathrm{~L}), V^{\prime}{ }_{\mathrm{D}}$ must have been high from the beginning, with a limited further increase of total $V_{\mathrm{E}}^{\prime}$ during exercise, as happens in COPD [12]. Conversely, if the Y-intercept is below its normal value, it suggests a progressive increase of $V_{D}^{\prime}$ during exercise as is the case in heart failure, and, to a greater extent, in patients with pulmonary hypertension with and without heart failure. In these cases, the Y-intercept may even have a negative value $[17,19,20]$. Indeed, in a large multicentre study, AроsтоLо and co-workers $[12,93,94]$ showed that, in heart failure, an 
elevated Y-intercept implies the coexistence of COPD, while a Y-intercept value close to 0 or negative implies the coexistence of pulmonary hypertension.

Special attention should be dedicated to the $V_{\mathrm{E}}^{\prime}$ versus $V_{\mathrm{CO}_{2}}^{\prime}$ relationship analysis during exercise in patients with heart failure and associated comorbidities such as anxiety/depression, obesity, lung disease, kidney dysfunction and anaemia [95]. Anxiety influences the ventilatory behaviour of heart failure patients as well as that of normal subjects, but usually only in the early phase of exercise. At the beginning of exercise and even before exercise, $V_{\mathrm{E}}^{\prime}$ increases, so that the $\mathrm{CO}_{2}$ stored in the body deposits and $P_{\mathrm{ETCO}_{2}}$ decrease, while $V^{\prime}{ }_{\mathrm{E}} / V^{\prime} \mathrm{CO}_{2}$ ratio increases. As a consequence, the capability to buffer lactic acid is reduced, and so is the length of the isocapnic buffering period; moreover, the capability to identify the AT by ventilatory equivalents is hampered, as is the physiological meaning of $P_{\mathrm{ETCO}}$ and of $V_{\mathrm{E}}^{\prime}$ versus $V^{\prime} \mathrm{CO}_{2}$ relationship. Depression, which is a frequent and dangerous comorbidity of heart failure, reduces the capacity/willingness of patients to perform a maximal exercise, so that the meaning of peak $V^{\prime} \mathrm{O}_{2}$ is questionable in these patients. However, this does not affect the $V_{\mathrm{E}}^{\prime}$ versus $V^{\prime} \mathrm{CO}_{2}$ relationship slope, which is likely to become the most powerful indicator of heart failure severity and prognosis in these patients. As regards heart failure patients with obesity, Piepoli et al. [96] reported a progressive reduction of the $V_{\mathrm{E}}^{\prime}$ versus $V_{\mathrm{CO}_{2}}^{\prime}$ slope in parallel with body mass index increase. However, peak $V_{\mathrm{O}_{2}}^{\prime}$ and ventricular ejection fraction also increased, so that the presence of a specific behaviour of the $V_{\mathrm{E}}^{\prime}$ versus $V_{\mathrm{CO}_{2}}^{\prime}$ slope in overweight heart failure patients is still unknown. Lung diseases are frequently reported comorbidities of heart failure, influencing the treatment and prognosis of both heart failure and lung disease. Specifically, CPET is heavily influenced by the combination of heart failure and lung disease, so that $P_{\mathrm{ETCO}_{2}}$ can progressively increase in patients with $\mathrm{CO}_{2}$ retention, the $\mathrm{Y}$-axis intercept of $V_{\mathrm{E}}^{\prime}$ versus $V_{\mathrm{CO}_{2}}^{\prime}$ relationship slope (figure 4) is high, but, most importantly, the meaning of the $V_{\mathrm{E}}^{\prime}$ versus $V_{\mathrm{CO}_{2}}^{\prime}$ slope becomes uncertain for heart failure severity assessment and prognosis $[12,18,93]$. In addition, renal insufficiency is frequently associated with heart failure, and it is actually a part of the heart failure syndrome. SCRUTINIO et al. [97] showed, in a population of almost 3000 heart failure patients, that the $V_{\mathrm{E}}^{\prime}$ versus $V^{\prime} \mathrm{CO}_{2}$ relationship slope was higher in patients with most severe renal impairment. Finally, anaemia deeply influences heart failure prognosis and directly affects peak $V_{\mathrm{O}_{2}}^{\prime}$ [98-100.] As regards the $V_{\mathrm{E}}^{\prime}$ versus $V^{\prime} \mathrm{CO}_{2}$ relationship in heart failure patients with anaemia, there is an unexpected but relevant finding. As a matter of fact, CATTADORI et al. [101] showed that, in a population of almost 4000 heart failure patients, $6 \%$ of cases had very low haemoglobin levels $\left(<11 \mathrm{~g} \cdot \mathrm{dL}^{-1}\right)$, while $17 \%$ had a haemoglobin value $>15 \mathrm{~g} \cdot \mathrm{dL}^{-1}$. In both groups, the $V_{\mathrm{E}}^{\prime}$ versus $V^{\prime} \mathrm{CO}_{2}$ relationship slope lost its prognostic power. The physiological reasons behind this finding are basically unknown, although a possible role of differences in peripheral $\mathrm{O}_{2}$ delivery and of the consequent metaboreflex on $V_{\mathrm{E}}^{\prime}$ can be speculated [102]. In any case, in the presence of heart failure comorbidities, the prognostic meaning of $V_{\mathrm{E}}^{\prime}$ versus $V^{\prime} \mathrm{CO}_{2}$ slope must be contextualised in each specific clinical setting.

\section{Conclusions}

In conclusion, in the complex clinical scenario of the heart failure syndrome, the ventilatory behaviour during exercise, its shape, and its relationship with $V^{\prime} \mathrm{CO}_{2}$ hide a variety of information useful for several features, including understanding the physiological cause of ventilatory abnormalities, assessing heart failure relationship with several comorbidities, grading heart failure severity, selecting therapy and planning heart failure follow-up. However, as frequently and erroneously done, we cannot relate to a single, good-for-all number. Indeed, we have to take into account when CPET was performed, patient's age, sex, concomitant treatments, and presence of heart failure comorbidities. Most importantly, we have to look at the $V_{\mathrm{E}}^{\prime}$ versus $V^{\prime} \mathrm{CO}_{2}$ relationship by visual inspection to evaluate its shape, changes during exercise and $\mathrm{Y}$-axis intercept of the relationship from the beginning of exercise to RCP, but also, separately, from RCP to peak exercise. Finally, $V_{\mathrm{E}}^{\prime}$ versus $V^{\prime} \mathrm{CO}_{2}$ relationship values, regardless of how they are measured, must be integrated with several clinical and laboratory data to build the most precise mosaic of our heart failure subject with the aim of precisely tailoring their treatment.

Conflict of interest: P. Agostoni reports non-financial support from Menarini, grants from Daiichi Sankyo and Bayer; non-financial support from Novartis and Boehringer; and grants and non-financial support from Actelion, outside the submitted work. S. Sciomer has nothing to disclose. P. Palermo reports personal fees from Novartis and Malesci, outside the submitted work. M. Contini reports personal fees and non-financial support from Dompé Farmaceutici S.p.A. and personal fees from Novartis, outside the submitted work. B. Pezzuto has nothing to disclose. S. Farina has nothing to disclose. A. Magini has nothing to disclose. F. De Martino has nothing to disclose. D. Magrì has nothing to disclose. S. Paolillo has nothing to disclose. G. Cattadori has nothing to disclose. C. Vignati has nothing to disclose. M. Mapelli has nothing to disclose. A. Apostolo has nothing to disclose. E. Salvioni has nothing to disclose.

\section{References}

$1 \quad$ Wasserman K. Breathing during exercise. N Engl J Med 1978; 298: 780-785. 
Chua TP, Ponikowski P, Harrington D, et al. Clinical correlates and prognostic significance of the ventilatory response to exercise in chronic heart failure. J Am Coll Cardiol 1997; 29: 1585-1590.

3 Carriere C, Corrà U, Piepoli M, et al. Isocapnic buffering period: from physiology to clinics. Eur J Prev Cardiol 2019; 26: 1107-1114.

4 Whipp BJ, Davis JA, Wasserman K. Ventilatory control of the 'isocapnic buffering' region in rapidly-incremental exercise. Respir Physiol 1989; 76: 357-367.

5 Tanehata M, Adachi H, Oshima S, et al. The time from anaerobic threshold (AT) to respiratory compensation point reflects the rate of aerobic and anaerobic metabolism after the AT in chronic heart failure patients. Jpn Circ J 1999; 63: 274-277.

6 Agostoni P, Valentini M, Magrí D, et al. Disappearance of isocapnic buffering period during increasing work rate exercise at high altitude. Eur J Cardiovasc Prev Rehabil 2008; 15: 354-358.

7 Yen YS, Su DCJ, Yuan KS, et al. Isocapnic buffering phase: a useful indicator of exercise endurance in patients with coronary artery disease. Phys Sportsmed 2018; 46: 228-232.

8 Carriere C, Corrà U, Piepoli M, et al. Anaerobic threshold and respiratory compensation point identification during cardiopulmonary exercise tests in chronic heart failure. Chest 2019; 156: 338-347.

9 Westhoff M, Rühle KH, Greiwing A, et al. Ventilatorische und metabolische (Laktat-)Schwellen Positionspapier der Arbeitsgemeinschaft Spiroergometrie. [Positional paper of the German working group "cardiopulmonary exercise testing" to ventilatory and metabolic (lactate) thresholds]. Dtsch Med Wochenschr 2013; 138: 275-280.

10 Agostoni P, Dumitrescu D. How to perform and report a cardiopulmonary exercise test in patients with chronic heart failure. Int J Cardiol 2019; 288: 107-113.

11 Agostoni P, Corrà U, Cattadori G, et al. Prognostic value of indeterminable anaerobic threshold in heart failure. Circ Heart Fail 2013; 6: 977-987.

12 Apostolo A, Laveneziana P, Palange $\mathrm{P}$, et al. Impact of chronic obstructive pulmonary disease on exercise ventilatory efficiency in heart failure. Int J Cardiol 2015; 189: 134-140.

13 Agostoni P, Apostolo A, Cattadori G, et al. Effects of $\beta$-blockers on ventilation efficiency in heart failure. Am Heart J 2010; 159: 1067-1073.

14 Wensel R, Georgiadou P, Francis DP, et al. Differential contribution of dead space ventilation and low arterial $\mathrm{pCO}_{2}$ to exercise hyperpnea in patients with chronic heart failure secondary to ischemic or idiopathic dilated cardiomyopathy. Am J Cardiol 2004; 93: 318-323.

15 Robertson HT. Dead space: the physiology of wasted ventilation. Eur Respir J 2015; 45: 1704-1716.

16 Farina S, Bruno N, Agalbato C, et al. Physiological insights of exercise hyperventilation in arterial and chronic thromboembolic pulmonary hypertension. Int J Cardiol 2018; 259: 178-182.

17 Van Iterson EH, Johnson BD, Borlaug BA, et al. Physiological dead space and arterial carbon dioxide contributions to exercise ventilatory inefficiency in patients with reduced or preserved ejection fraction heart failure. Eur J Heart Fail 2017; 19: 1675-1685.

18 Gargiulo P, Apostolo A, Perrone-Filardi P, et al. A non invasive estimate of dead space ventilation from exercise measurements. PLoS One 2014; 9: e87395.

19 Farina S, Correale M, Bruno N, et al. The role of cardiopulmonary exercise tests in pulmonary arterial hypertension. Eur Respir Rev 2018; 27: 170134.

20 Agostoni P, Farina S, Apostolo A, et al. Inside ventilatory regulation in pulmonary hypertension: several hidden data are still undiscovered. Eur J Prev Cardiol 2014; 21: 268-271.

21 MacGowan GA, Janosko K, Cecchetti A, et al. Exercise-related ventilatory abnormalities and survival in congestive heart failure. Am J Cardiol 1997; 79: 1264-1266.

22 Robbins M, Francis G, Pashkow FJ, et al. Ventilatory and heart rate responses to exercise: better predictors of heart failure mortality than peak oxygen consumption. Circulation 1999; 100: 2411-2417.

23 de Jonge N, Kirkels H, Lahpor JR, et al. Exercise performance in patients with end-stage heart failure after implantation of a left ventricular assist device and after heart transplantation: an outlook for permanent assisting? J Am Coll Cardiol 2001; 37: 1794-1799.

24 Sun XG, Hansen JE, Garatachea N, et al. Ventilatory efficiency during exercise in healthy subjects. Am J Respir Crit Care Med 2002; 166: 1443-1448.

25 Myers J, Arena R, Oliveira RB, et al. The lowest $V^{\prime}{ }_{\mathrm{E}} / V^{\prime} \mathrm{CO}_{2}$ ratio during exercise as a predictor of outcomes in patients with heart failure. J Card Fail 2009; 15: 756-762.

26 Ingle L, Sloan R, Carroll S, et al. Prognostic significance of different measures of the ventilation-carbon dioxide relation in patients with suspected heart failure. Eur J Heart Fail 2011; 13: 537-542.

27 Bard RL, Gillespie BW, Clarke NS, et al. Determining the best ventilatory efficiency measure to predict mortality in patients with heart failure. J Heart Lung Transplant 2006; 25: 589-595.

28 Tabet JY, Beauvais F, Thabut G, et al. A critical appraisal of the prognostic value of the $V_{\mathrm{E}} / V_{\mathrm{CO} 2}$ slope in chronic heart failure. Eur J Cardiovasc Prev Rehabil 2003; 10: 267-272.

29 Salvioni E, Corrà U, Piepoli M, et al. Gender and age normalization and ventilation efficiency during exercise in heart failure with reduced ejection fraction. ESC Heart Fail 2020; 7: 371-380.

30 Francis DP, Shamim W, Davies LC, et al. Cardiopulmonary exercise testing for prognosis in chronic heart failure: continuous and independent prognostic value from $V_{\mathrm{E}} / V_{\mathrm{CO} 2}$ slope and peak $V_{\mathrm{O}_{2}}$. Eur Heart J 2000; 21 : 154-161.

31 Arena R, Myers J, Guazzi M. The clinical and research applications of aerobic capacity and ventilatory efficiency in heart failure: an evidence-based review. Heart Fail Rev 2008; 13: 245-269.

32 Guazzi M, Adams V, Conraads V, et al. EACPR/AHA Scientific Statement. Clinical recommendations for cardiopulmonary exercise testing data assessment in specific patient populations. Circulation 2012; 126: 2261-2274.

33 Balady GJ, Arena R, Sietsema K, et al. Clinician's Guide to cardiopulmonary exercise testing in adults: a scientific statement from the American Heart Association. Circulation 2010; 122: 191-225.

34 Kleber FX, Vietzke G, Wernecke KD, et al. Impairment of ventilatory efficiency in heart failure: prognostic impact. Circulation 2000; 101: 2803-2809.

35 Koch B, Schäper C, Ittermann T, et al. Reference values for cardiopulmonary exercise testing in healthy volunteers: the SHIP study. Eur Respir J 2009; 33: 389-397.

36 Neder JA, Nery LE, Peres C, et al. Reference values for dynamic responses to incremental cycle ergometry in males and females aged 20 to 80. Am J Respir Crit Care Med 2001; 164: 1481-1486. 
Poulin MJ, Cunningham DA, Paterson DH, et al. Ventilatory response to exercise in men and women 55 to 86 years of age. Am J Respir Crit Care Med 1994; 149: 408-415.

Robertson HT, Pellegrino R, Pini D, et al. Exercise response after rapid intravenous infusion of saline in healthy humans. J Appl Physiol 2004; 97: 697-703.

Paolillo S, Pellegrino R, Salvioni E, et al. Role of alveolar $\beta 2$-adrenergic receptors on lung fluid clearance and exercise ventilation in healthy humans. PLoS One 2013; 8: e61877.

Mutlu GM, Koch WJ, Factor P. Alveolar epithelial $\beta_{2}$-adrenergic receptors: their role in regulation of alveolar active sodium transport. Am J Respir Crit Care Med 2004; 170: 1270-1275.

Mutlu GM, Factor P. Alveolar epithelial $\beta_{2}$-adrenergic receptors. Am J Respir Cell Mol Biol 2008; 38: 127-134.

Malfatto G, Caravita S, Giglio A, et al. Pulmonary congestion at rest and abnormal ventilation during exercise in chronic systolic heart failure. J Am Heart Assoc 2015; 4: e001678.

Windsor JS, Rodway GW. Supplemental oxygen effects on ventilation in acclimatized subjects exercising at $5700 \mathrm{~m}$ altitude. Aviat Space Environ Med 2007; 78: 426-429.

Lawler J, Powers SK, Thompson D. Linear relationship between VO2max and VO2max decrement during exposure to acute hypoxia. J Appl Physiol 1988; 64: 1486-1492.

Ward SA, Grocott MPW, Levett DZH. Exercise testing, supplemental oxygen, and hypoxia. Ann Am Thorac Soc 2017; 14: S140-S148.

Valentini M, Revera M, Bilo G, et al. Effects of $\beta$-blockade on exercise performance at high altitude: a randomized, placebo-controlled trial comparing the efficacy of nebivolol versus carvedilol in healthy subjects. Cardiovasc Ther 2012; 30: 240-248.

Agostoni P, Contini M, Magini A, et al. Carvedilol reduces exercise-induced hyperventilation: a benefit in normoxia and a problem with hypoxia. Eur J Heart Fail 2006; 8: 729-735.

Wasserman K, Zhang YY, Gitt A, et al. Lung function and exercise gas exchange in chronic heart failure. Circulation 1997; 96: 2221-2227.

Mezzani A, Giordano A, Komici K, et al. Different determinants of ventilatory inefficiency at different stages of reduced ejection fraction chronic heart failure natural history. J Am Heart Assoc 2017; 6: e005278.

Agostoni P, Guazzi M. Exercise ventilatory inefficiency in heart failure: some fresh news into the roadmap of heart failure with preserved ejection fraction phenotyping. Eur J Heart Fail 2017; 19: 1686-1689.

Ponikowski P, Francis DP, Piepoli MF, et al. Enhanced ventilatory response to exercise in patients with chronic heart failure and preserved exercise tolerance: marker of abnormal cardiorespiratory reflex control and predictor of poor prognosis. Circulation 2001; 103: 967-972.

Gitt AK, Wasserman K, Kilkowski C, et al. Exercise anaerobic threshold and ventilatory efficiency identify heart failure patients for high risk of early death. Circulation 2002; 106: 3079-3084.

Mejhert M, Linder-Klingsell E, Edner M, et al. Ventilatory variables are strong prognostic markers in elderly patients with heart failure. Heart 2002; 88: 239-243.

Corrà U, Pistono M, Mezzani A, et al. Sleep and exertional periodic breathing in chronic heart failure: prognostic importance and interdependence. Circulation 2006; 113: 44-50.

Davies LC, Wensel R, Georgiadou P, et al. Enhanced prognostic value from cardiopulmonary exercise testing in chronic heart failure by non-linear analysis: oxygen uptake efficiency slope. Eur Heart J 2006; 27: 684-690.

Nanas S, Anastasiou-Nana M, Dimopoulos S, et al. Early heart rate recovery after exercise predicts mortality in patients with chronic heart failure. Int J Cardiol 2006; 110: 393-400.

Jankowska EA, Witkowski T, Ponikowska B, et al. Excessive ventilation during early phase of exercise: a new predictor of poor long-term outcome in patients with chronic heart failure. Eur J Heart Fail 2007; 9: 1024-1031.

Guimaraes GV, Silva MS, d'Avila VM, et al. Peak $\mathrm{VO}_{2}$ and $\mathrm{VE} / \mathrm{VCO}_{2}$ slope in betablockers era in patients with heart failure: a Brazilian experience. Arq Bras Cardiol 2008; 91: 39-48.

Pascual-Figal DA, Penafiel P, Nicolas F, et al. Valor pronóstico del BNP y la prueba de esfuerzo cardiopulmonar en la insuficiencia cardiaca sistólica en tratamiento con bloqueadores beta. [Prognostic value of BNP and cardiopulmonary exercise testing in patients with systolic heart failure on beta-blocker therapy]. Rev Esp Cardiol 2008; 61: 260-268.

Myers J, Christle JW, Tun A, et al. Cardiopulmonary exercise testing, impedance cardiography, and reclassification of risk in patients referred for heart failure evaluation. J Card Fail 2019; 25: 961-968.

Poggio R, Arazi HC, Giorgi M, et al. Prediction of severe cardiovascular events by VE/VCO2 slope versus peak $\mathrm{VO}_{2}$ in systolic heart failure: a meta-analysis of the published literature. Am Heart J 2010; 160: 1004-1014.

Arena R, Myers J, Abella J, et al. Development of a ventilatory classification system in patients with heart failure. Circulation 2007; 115: 2410-2417.

Aaronson KD, Schwartz JS, Chen TM, et al. Development and prospective validation of a clinical index to predict survival in ambulatory patients referred for cardiac transplant evaluation. Circulation 1997; 95: 2660-2667.

Agostoni P, Corrà U, Cattadori G, et al. Metabolic exercise test data combined with cardiac and kidney indexes, the MECKI score: a multiparametric approach to heart failure prognosis. Int J Cardiol 2013; 167: 2710-2718.

Guazzi M, Boracchi P, Arena R, et al. Development of a cardiopulmonary exercise prognostic score for optimizing risk stratification in heart failure: the $(\mathrm{P}) \mathrm{e}(\mathrm{R}) \mathrm{i}(\mathrm{O})$ dic $(\mathrm{B})$ reathing during $(\mathrm{E})$ xercise (PROBE) study. $J$ Card Fail 2010; 16: 799-805.

Levy WC, Aaronson KD, Dardas TF, et al. Prognostic impact of the addition of peak oxygen consumption to the Seattle Heart Failure Model in a transplant referral population. J Heart Lung Transplant 2012; 31: 817-824.

Myers J, Arena R, Dewey F, et al. A cardiopulmonary exercise testing score for predicting outcomes in patients with heart failure. Am Heart J 2008; 156: 1177-1183.

Myers J, Oliveira R, Dewey F, et al. Validation of a cardiopulmonary exercise test score in heart failure. Circ Heart Fail 2013; 6: 211-218.

O'Connor CM, Whellan DJ, Wojdyla D, et al. Factors related to morbidity and mortality in patients with chronic heart failure with systolic dysfunction: the HF-ACTION predictive risk score model. Circ Heart Fail 2011; 5: 63-71.

Kato TS, Stevens GR, Jiang J, et al. Risk stratification of ambulatory patients with advanced heart failure undergoing evaluation for heart transplantation. J Heart Lung Transplant 2013; 32: 333-340. 
Stempfle HU, Alt A, Stief J, et al. The Munich score: a clinical index to predict survival in ambulatory patients with chronic heart failure in the era of new medical therapies. J Heart Lung Transplant 2008; 27: 222-228.

Lanfranchi PA, Braghiroli A, Bosimini E, et al. Prognostic value of nocturnal Cheyne-Stokes respiration in chronic heart failure. Circulation 1999; 99: 1435-1440.

Arzt M, Harth M, Luchner A, et al. Enhanced ventilatory response to exercise in patients with chronic heart failure and central sleep apnea. Circulation 2003; 107: 1998-2003.

Nadruz W Jr, West E, Sengeløv M, et al. Prognostic value of cardiopulmonary exercise testing in heart failure with reduced, midrange, and preserved ejection fraction. J Am Heart Assoc 2017; 6: e006000.

Carubelli V, Metra $\mathrm{M}$, Corrà $\mathrm{U}$, et al. Exercise performance is a prognostic indicator in elderly patients with chronic heart failure - application of metabolic exercise cardiac kidney indexes score. Circ J 2015; 79: 2608-2615. Paolillo S, Veglia F, Salvioni E, et al. Heart failure prognosis over time: how the prognostic role of oxygen consumption and ventilatory efficiency during exercise has changed in the last 20 years. Eur J Heart Fail 2019; 21: 208-217.

Contini M. Cardiopulmonary exercise test as a tool to choose therapy in heart failure. Ann Am Thorac Soc 2017; 14: S67-S73.

Guazzi M, Marenzi G, Alimento M, et al. Improvement of alveolar-capillary membrane diffusing capacity with enalapril in chronic heart failure and counteracting effect of aspirin. Circulation 1997; 95: 1930-1936.

Guazzi M, Palermo P, Pontone G, et al. Synergistic efficacy of enalapril and losartan on exercise performance and oxygen consumption at peak exercise in congestive heart failure. Am J Cardiol 1999; 84: 1038-1043.

Agostoni P, Magini A, Andreini D, et al. Spironolactone improves lung diffusion in chronic heart failure. Eur Heart J 2005; 26: 159-164.

Scott AC, Wensel $\mathrm{R}$, Davos $\mathrm{CH}$, et al. Putative contribution of prostaglandin and bradykinin to muscle reflex hyperactivity in patients on Ace-inhibitor therapy for chronic heart failure. Eur Heart J 2004; 25: 1806-1813.

Kataoka M, Satoh T, Yoshikawa T, et al. Comparison of the effects of carvedilol and metoprolol on exercise ventilatory efficiency in patients with congestive heart failure. Circ J 2008; 72: 358-363.

Laveneziana P, Agostoni P, Mignatti A, et al. Effect of acute $\beta$-blocker withholding on ventilatory efficiency in patients with advanced chronic heart failure. J Card Fail 2010; 16: 548-555.

Contini M, Apostolo A, Cattadori G, et al. Multiparametric comparison of CARvedilol, vs. NEbivolol, vs. BIsoprolol in moderate heart failure: the CARNEBI trial. Int J Cardiol 2013; 168: 2134-2140.

Vitale G, Romano G, Di Franco A, et al. Early effects of sacubitril/valsartan on exercise tolerance in patients with heart failure with reduced ejection fraction. J Clin Med 2019; 8: 262.

Magrì D, Santolamazza C. Cardiopulmonary exercise test in hypertrophic cardiomyopathy. Ann Am Thorac Soc 2017; 14: S102-S109.

Arena R, Owens DS, Arevalo J, et al. Ventilatory efficiency and resting hemodynamics in hypertrophic cardiomyopathy. Med Sci Sports Exerc 2008; 40: 799-805.

Ong KC, Geske JB, Hebl VB, et al. Pulmonary hypertension is associated with worse survival in hypertrophic cardiomyopathy. Eur Heart J Cardiovasc Imaging 2016; 17: 604-610.

Magri D, Limongelli G, Re F, et al. Cardiopulmonary exercise test and sudden cardiac death risk in hypertrophic cardiomyopathy. Heart 2016; 102: 602-609.

Magrì D, Re F, Limongelli G, et al. Heart failure progression in hypertrophic cardiomyopathy - possible insights from cardiopulmonary exercise testing. Circ J 2016; 80: 2204-2211.

Sinagra G, Iorio A, Merlo M, et al. Prognostic value of cardiopulmonary exercise testing in idiopathic dilated cardiomyopathy. Int J Cardiol 2016; 223: 596-603.

Yunis A, Doros G, Luptak I, et al. Use of ventilatory efficiency slope as a marker for increased mortality in wild-type transthyretin cardiac amyloidosis. Am J Cardiol 2019; 124: 122-130.

Smith JR, Van Iterson $\mathrm{EH}$, Johnson $\mathrm{BD}$, et al. Exercise ventilatory inefficiency in heart failure and chronic obstructive pulmonary disease. Int J Cardiol 2019; 274: 232-236.

Teopompi E, Tzani P, Aiello M, et al. Ventilatory response to carbon dioxide output in subjects with congestive heart failure and in patients with COPD with comparable exercise capacity. Respir Care 2014; 59: 1034-1041. comorbidities. Ann Am Thorac Soc 2017; 14: S110-S115.

Piepoli MF, Corrà U, Veglia F, et al. Exercise tolerance can explain the obesity paradox in patients with systolic heart failure: data from the MECKI Score Research Group. Eur J Heart Fail 2016; 18: 545-553.

Scrutinio D, Agostoni P, Gesualdo L, et al. Renal function and peak exercise oxygen consumption in chronic heart failure with reduced left ventricular ejection fraction. Circ J 2015; 79: 583-591.

Berry C, Poppe KK, Gamble GD, et al. Prognostic significance of anaemia in patients with heart failure with preserved and reduced ejection fraction: results from the MAGGIC individual patient data meta-analysis. QJM 2016; 109: 377-382.

Mentz RJ, Kelly JP, von Lueder TG, et al. Noncardiac comorbidities in heart failure with reduced versus preserved ejection fraction. J Am Coll Cardiol 2014; 64: 2281-2293.

Circulation 2018; 138: 80-98.

Cattadori G, Agostoni P, Corrà U, et al. Heart failure and anemia: effects on prognostic variables. Eur J Intern Med 2017; 37: 56-63.

Segreti A, Grigioni F, Campodonico J, et al. Chemoreceptor hyperactivity in heart failure: is lactate the culprit? Eur J Prev Cardiol 2020; in press [https://doi.org/10.1177/2047487320915548]. 